\title{
Evaluation of dacryocystorhinostomy using optical coherence tomography and rebamipide ophthalmic suspension
}

This article was published in the following Dove Press journal:

Clinical Ophthalmology

I August 2014

Number of times this article has been viewed

\author{
Masahiro Fujimoto' \\ Ken Ogino' \\ Chika Miyazaki ${ }^{1,2}$ \\ Miou Hirose ${ }^{1,3}$ \\ Hiroko Matsuyama ${ }^{1,4}$ \\ Takeshi Moritera ${ }^{1,5}$ \\ Nagahisa Yoshimura' \\ 'Department of Ophthalmology \\ and Visual Sciences, Kyoto University \\ Graduate School of Medicine, Kyoto, \\ Japan; ${ }^{2}$ Department of Ophthalmology, \\ Hyogo Prefectural Tsukaguchi \\ Hospital, Hyogo, Japan; ${ }^{3}$ Department \\ of Ophthalmology, Hyogo Prefectural \\ Amagasaki Hospital, Hyogo, Japan; \\ ${ }^{4}$ Department of Ophthalmology, \\ National Hospital Organization \\ Himeji Medical Center, Hyogo, Japan; \\ ${ }^{5}$ Moritera Eye Clinic, Shiga, Japan
}

Correspondence: Ken Ogino Department of Ophthalmology and Visual Sciences, Kyoto University Graduate School of Medicine, 54 Shogoin Kawaharacho, Sakyo-ku, Kyoto 606-8507, Japan

Tel $+8 \mid 7575$ I 3250

Fax +8I 75 75। 0933

Email kenboo@kuhp.kyoto-u.ac.jp
Purpose: To evaluate the surgical outcome of dacryocystorhinostomy (DCR) by measuring the tear meniscus, using optical coherence tomography and rebamipide ophthalmic suspension.

Methods: Patients with nasolacrimal obstruction and chronic dacryocystitis who were scheduled for an endonasal DCR underwent tear meniscus examinations before and 2 months after surgery. Vertical scans of the inferior menisci were performed before and at 1, 3, 5, 7, and 10 minutes after the instillation of rebamipide ophthalmic suspension. The tear menisci areas were measured with imaging software. Ten young adults without epiphora formed the control group.

Results: Anatomical success was achieved on 22 sides of 21 patients. The patients' postoperative tear menisci were significantly smaller than the preoperative menisci at all points during the test, and the response to volume loading in the postoperative patients was corrected to nearly that of the young, healthy adults. Nevertheless, the postoperative meniscus area tended to be larger than that of the young adults at all points.

Conclusion: The reduced tear meniscus area after DCR reflected the success of the surgical procedure. However, incomplete recovery of the meniscus after the test might suggest a residual disorder of the lacrimal drainage system after DCR.

Keywords: dacryocystorhinostomy, tear meniscus, rebamipide, optical coherence tomography

\section{Introduction}

Treatment of nasolacrimal duct obstruction by external or endonasal dacryocystorhinostomy (DCR) has been highly successful. ${ }^{1-3}$ However, anatomic success does not always indicate an improvement in epiphora. ${ }^{46}$ Residual epiphora after DCR is speculated to be caused by a loss of the pumping function present in a normal lacrimal drainage system $;^{7}$ however, it has been difficult to quantify residual epiphora. Munk's score is a very popular and easy method to evaluate epiphora, but it is subjective. ${ }^{8} \mathrm{We}$ hypothesized that an objective and easily available quantification would elucidate the pathogenesis of functional nasolacrimal drainage obstruction, including residual epiphora, after DCR.

Optical coherence tomography (OCT) was developed in 1991 for the noninvasive visualization of the vitreoretinal interface and retinal structure. ${ }^{9}$ Recently, the use of OCT has also been reported in anterior segment disease such as primary angle closure, ${ }^{10}$ corneal disease, ${ }^{11}$ dry eye, ${ }^{12}$ and epiphora secondary to nasolacrimal duct obstruction. ${ }^{13}$ Johnson and Murphy measured the tear meniscus using OCT for the first time, ${ }^{14}$ which represents the greater portion of the tear volume located between the cornea and eyelid. Then, Ibrahim et al determined that an OCT-based measurement of the tear meniscus was useful for the diagnosis of dry eye, ${ }^{12}$ and Park et al used OCT 
to show differences in tear menisci between normal subjects and patients with watery eyes. ${ }^{13}$ Therefore, a detailed and modified observation of the tear meniscus by OCT could provide more information regarding epiphora because of functional nasolacrimal obstruction.

In Japan, rebamipide ophthalmic suspension has been used for the treatment of dry eye since 2011, and its effectiveness has been reported in a randomized controlled trial. ${ }^{15}$ Originally, rebamipide was used to prevent acute gastric mucosal lesions or recurrence of chronic gastric ulcers because of its mucin secretagogue activity. ${ }^{16,17}$ Rebamipide suspension contains $2 \mu \mathrm{m}$ wide white particles and is clearly visible in the tear meniscus for minutes after instillation by slit-lamp microscopy. Our preliminary experiment found that rebamipide was also well-visualized by OCT. In contrast, neither artificial tears nor fluorescein dye enhanced the tear meniscus on OCT. Moreover, loading of the eye drop is thought to mimic the condition in which tear secretion is increased by stimulation of the ocular surface.

This prospective study was conducted to determine the extent to which the tear menisci of patients with nasolacrimal obstruction would normalize after DCR by using OCT and rebamipide suspension. We evaluated the differences in tear menisci between patients and young healthy volunteers as well as the changes in tear menisci before and after DCR. This observation would explain the residual epiphora after DCR.

\section{Methods}

This prospective study was registered with the University hospital Medical Information Network Clinical Trials Registry system (UMIN000009494). This study was approved by the Institutional Review Board at Kyoto University Graduate School of Medicine and Hyogo Prefectural Tsukaguchi Hospital and adhered to the tenets of the Declaration of Helsinki (E-1638). Written informed consent for research participation was obtained from each subject before examination.

\section{Participants}

Patients with nasolacrimal duct obstruction scheduled for DCR treatment at Kyoto University Graduate School of Medicine and Hyogo Prefectural Tsukaguchi Hospital from February 2013 to June 2013 were prospectively enrolled in this study. All patients were diagnosed with chronic dacryocystitis secondary to nasolacrimal duct obstruction. Chronic dacryocystitis and nasolacrimal duct obstruction were diagnosed by the presence of regurgitation by syringing test and observation using dacryoendoscopy (FiberTech, Tokyo, Japan), respectively. We confirmed the absence of an endonasal abnormality interfering with DCR on computed tomography imaging and with an endonasal endoscope. Patients with canalicular obstruction or punctal occlusion were excluded from this study. The enrolled patients were followed-up for 2 months after surgery by OCT examination, the syringing test, and endonasal endoscopic observation. In addition, ten young healthy volunteers (mean age, $33.6 \pm 6.5$ years; four men and six women) were enrolled in the control group. The young healthy volunteers presented no epiphora or abnormal tear meniscus height based on an interview and slit-lamp bioscopy.

\section{Surgical procedures}

Endonasal DCR was performed by $\mathrm{CM}$ and $\mathrm{MH}$, using the standard technique, primarily under local anesthesia with sedation (midazolam). Briefly, the lateral nasal wall anterior and superior to the middle turbinate was infiltrated with $2 \%$ lidocaine and 1:1,000 epinephrine solution. In addition, an infratrochlear nerve block and intracanalicular anesthesia were performed with $2 \%$ lidocaine. Under an endonasal endoscope (Hopkins wide-angle stereoscope $0^{\circ}$; Karl Storz, Tuttlingen, Germany) and guided by a 23-gauge light pipe (Bright Star, DORC, the Netherlands) inserted in the lacrimal sac through the lacrimal puncta, the nasal mucosa were removed from the anterior segment of the maxilla to the base of the middle nasal concha by using a cut blade (Medtronic, Minneapolis, MN, USA), and the bones behind the lacrimal sac were exposed. The exposed maxilla, lacrimal bone, and anterior part of the unciform process were removed from the lacrimal sac at the level of the common canaliculus to the upper nasolacrimal duct with a curved diamond DCR bur (Medtronic), which resulted in a $1 \mathrm{~cm} \times 1 \mathrm{~cm}$ rhinotomy width. The exposed lacrimal sac was incised with a keratome, and a polyurethane tube was inserted through the inferior and superior canaliculus into the nose and later removed 2 months after surgery.

\section{Examination of the participants}

We used the anterior segment 5 line raster scanning protocol on a Cirrus HD-OCT system (Carl Zeiss Meditec, Dublin, CA, USA). The tear meniscus was vertically scanned along the middle of the lower eyelid, and a section through the corneal center was selected from among 5 sections for analysis. The participants were instructed to avoid using eye drops for 1 hour before testing. They placed their chin on a rest at the time of image capture and looked straight ahead while being 
allowed to blink freely. A drop of rebamipide $(43.8 \pm 2.4 \mu \mathrm{L})$ was instilled into the eye of the participant after tapping to avoid precipitation. Examinations were performed by trained technicians before and at 1, 3, 5, 7, and 10 minutes after rebamipide instillation. Patients with nasolacrimal duct obstruction underwent an OCT examination before DCR and after removal of the stent 2 months after surgery. The temperature and humidity of the test room were set at $25^{\circ} \mathrm{C} \pm 1^{\circ} \mathrm{C}$ and $30 \% \pm 5 \%$, respectively. The captured images were converted to grayscale and exported as bitmap files $(750 \times 500$ pixels). The tear menisci were manually outlined, using a polygonal selection tool from a free software package (ImageJ 1.46r, National Institutes of Health, Bethesda, MD, USA). Then, the size was automatically calculated, using the histogram tool.

\section{Statistical analysis}

All parametric values are presented as mean \pm standard deviation. The parameters before and after surgery, which were normally distributed, were compared using paired $t$-tests with Bonferroni corrections. The serial values obtained during single tests were analyzed by a repeated measures analysis of variance and post hoc tests with Bonferroni corrections. Statistical analyses were performed using SPSS statistics version 20 (IBM, Armonk, NY, USA).

\section{Results}

Twenty-two eyes of 21 patients with dacryocystitis secondary to nasolacrimal duct obstruction (mean age, $71.4 \pm 6.6$ years; six men and 15 women) were examined in this study. Surgical procedures were performed without any complications, and anatomical success was confirmed in all cases by performing a syringing test and an endonasal examination at the follow-up visit 2 months after surgery. The epiphora and discharge symptoms improved in all patients after DCR. The tear menisci are well depicted in Figure 1, particularly after rebamipide instillation, and the measurements are shown in Figure 2 and Table 1.

Before DCR, the tear meniscus area did not show a significant change before or after rebamipide eye drop instillation ( $P=0.326$; Table 1). After surgery, however, the tear meniscus area increased 1 minute after eye drop instillation $(P=0.00005)$ compared with that before application, and then decreased 3 minutes after instillation $(P=0.043)$. The tear meniscus area after DCR was significantly less than the area before surgery at all times, except at 1 minute after instillation (Table 1).

In the young healthy adults, the tear meniscus areas were $756 \pm 285,2,178 \pm 1,255,1,320 \pm 472,1,120 \pm 580,919 \pm 292$,

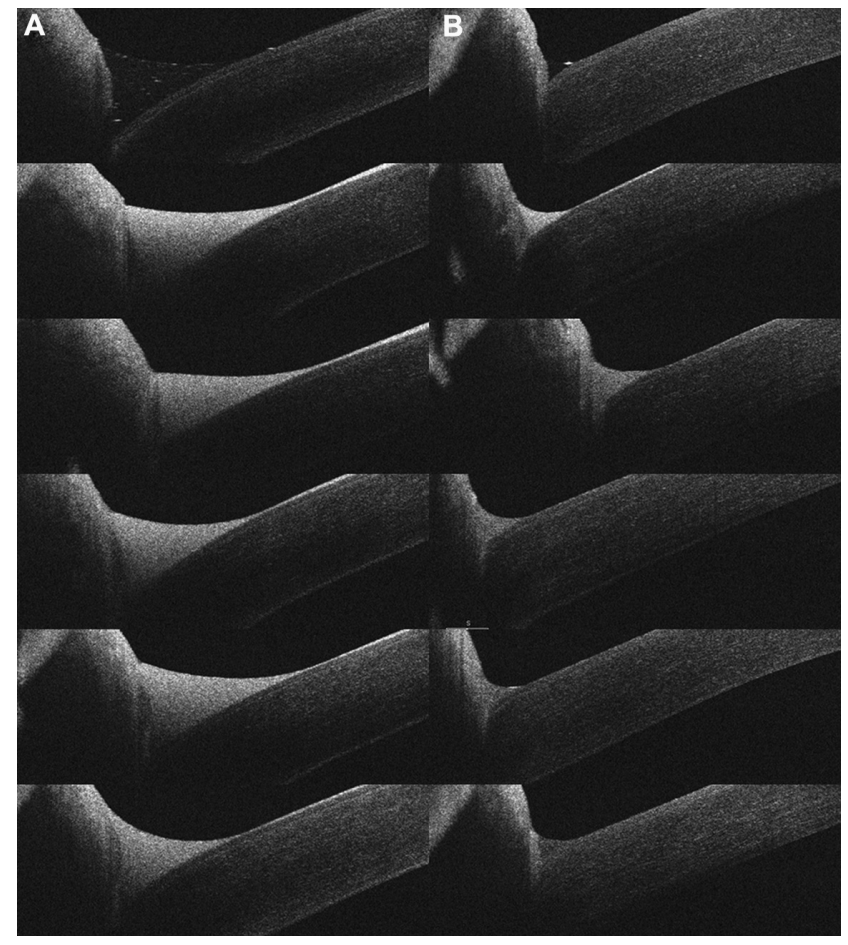

Figure I Optical coherence tomography images of the tear meniscus.

Notes: Serial images of the tear meniscus before $(\mathbf{A})$ and after $(\mathbf{B})$ an operation on a 70-year-old woman. The tear meniscus was measured before (Top) and at I, 3, 5, 7 , and 10 minutes (Bottom) after rebamipide instillation.

and $744 \pm 263$ pixels before and at 1,3,5, 7, and 10 minutes after rebamipide administration, respectively. Although the area of the tear meniscus in patients with nasolacrimal duct obstruction was reduced after DCR, the menisci of patients tended to be larger than those of young healthy adults at all times, even after surgery $(P=0.099,0.076,0.054,0.54,0.25$,

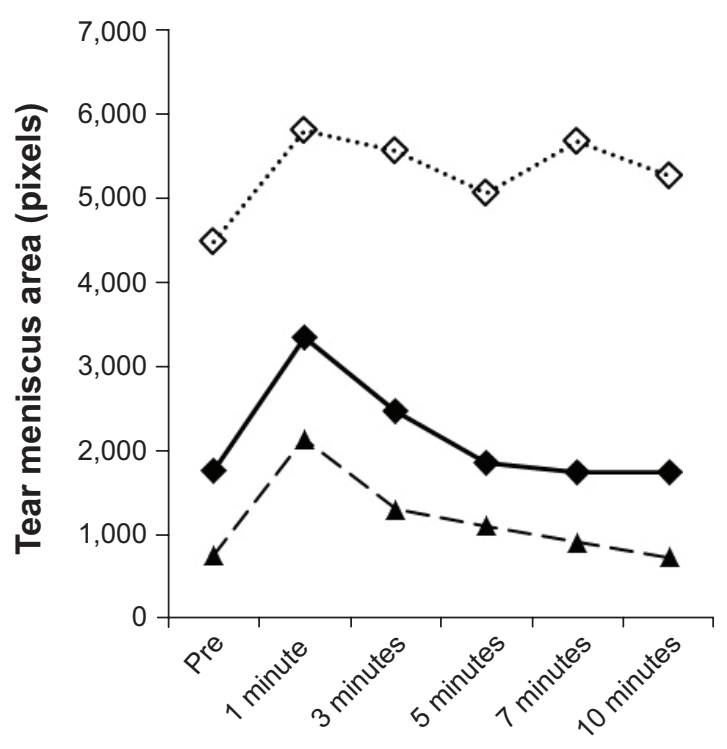

Figure 2 Changes in the tear meniscus area before the operation (open square), after the operation (closed square), and in healthy volunteers (triangle). 
Table I Comparisons of tear meniscus areas pre- and post-dacryocystorhinostomy

\begin{tabular}{llll}
\hline (Pixels) & Preoperatively & Postoperatively & P-value* \\
\hline Pre & $4,560 \pm 4,105$ & $1,799 \pm 1,844$ & $0.0049(0.029)$ \\
$I$ min & $5,916 \pm 4,843$ & $3,412 \pm 1,936$ & $0.018(0.11)$ \\
$3 \mathrm{~min}$ & $5,663 \pm 4,191$ & $2,512 \pm 1,863$ & $0.000004(0.000024)$ \\
$5 \mathrm{~min}$ & $5,158 \pm 3,572$ & $1,889 \pm 1,329$ & $0.000067(0.00040)$ \\
$7 \mathrm{~min}$ & $5,771 \pm 4,585$ & $1,778 \pm 1,819$ & $0.0051(0.031)$ \\
$10 \mathrm{~min}$ & $5,351 \pm 4,487$ & $1,779 \pm 1,365$ & $0.000597(0.0036)$ \\
$P$-value** & 0.326 & $<0.000001$ & \\
\hline
\end{tabular}

Notes: *Paired $t$-test (adjusted with a Bonferroni correction); **repeated analysis of variance.

and 0.012, respectively; unpaired $t$-test with a Bonferroni correction; Figure 2).

\section{Discussion}

We achieved anatomical success without any complications on 22 sides of 21 patients included in this study. The tear menisci of patients with nasolacrimal duct obstruction was reduced significantly after DCR, and the response to volume loading in the postoperative patients was corrected to nearly that of the young healthy adults. Even after surgery, however, the tear meniscus area tended to be larger than normal.

The recent development of the DCR technique has improved the anatomical success of nasolacrimal duct obstruction treatment. ${ }^{1-3}$ However, few patients experience epiphora, even after DCR. ${ }^{18}$ In these patients, DCR results in only a partial improvement of epiphora, and the watery eye condition remains. Although Smirnov et al established a symptom score questionnaire to assess the outcome of DCR, ${ }^{19}$ no objective, quantitative, and easy method has been made available to evaluate epiphora. Therefore, we proposed the use of OCT and a loading test with an ophthalmic suspension for the evaluation of epiphora.

First, our results were compatible with those of previous studies; that is, the mean tear meniscus area was reduced after surgery. ${ }^{20,21}$ The opening of the lacrimal sac into the nose might decrease the intrasac pressure and lead to a lower tear meniscus level. Second, normalization of the response to volume loading after DCR was a new finding. The normal volume of tear fluid in the tear meniscus is estimated to be $7 \mu \mathrm{L} .^{22}$ A drop of rebamipide almost entirely altered the tear, increasing the tear meniscus temporarily and then decreasing it gradually for 10 minutes in normal subjects and in patients after DCR. In contrast, patients with nasolacrimal duct obstruction before DCR had a higher tear meniscus, even before instillation, and showed no change in tear meniscus area after instillation, which implied a loss of drainage function. It was very interesting that the response to loading was recovered after surgery, but the effect was limited. In this study, all patients demonstrated improved symptoms after DCR. Nevertheless, lacrimal flow through the rhinotomy is not as great as that through a young healthy person's nasolacrimal duct. The difference might be derived from the pumping function present in the normal lacrimal drainage system.

This study has several limitations, especially with respect to the lack of age-matched controls without nasolacrimal obstruction. The use of age-matched controls would emphasize the effectiveness of DCR; however, there is a higher prevalence of epiphora in the elderly than in the young. To determine the residual abnormality after the operation, we considered that we should compare the conditions after DCR with a completely normal lacrimal drainage system. Second, as a drop of rebamipide overfilled the meniscus and most of the rebamipide seemed to spill out over the lid margin, not through the canaliculus, we do not know the exact amount of rebamipide applied to the tear meniscus. However, a drop of rebamipide mimics the increased secretion of tears after stimulation, and we can evaluate the drainage function under that condition.

In conclusion, the observation of the tear meniscus area using OCT and rebamipide demonstrated not only the efficacy of DCR for the treatment of nasolacrimal obstruction but also residual functional obstruction, even in asymptomatic patients after DCR. The difference in the tear meniscus between the postoperative patients and young healthy individuals might represent the estimated pumping function of the normal lacrimal drainage system.

\section{Acknowledgment}

We thank Yasushi Inoue, MD, from the Inoue Eye Clinic, for his helpful advice and ideas.

\section{Disclosure}

The authors report no conflicts of interest in this work. 


\section{References}

1. Al-Qahtani AS. Primary endoscopic dacryocystorhinostomy with or without silicone tubing: a prospective randomized study. Am J Rhinol Allergy. 2012;26(4):332-334.

2. Khalifa MA, Ragab SM, Saafan ME, El-Guindy AS. Endoscopic dacryocystorhinostomy with double posteriorly based nasal and lacrimal flaps: a prospective randomized controlled trial. Otolaryngology - head and neck surgery: official journal of American Academy of Otolaryngology. Head Neck Surg. 2012;147(4):782-787.

3. Zaidi FH, Symanski S, Olver JM. A clinical trial of endoscopic vs external dacryocystorhinostomy for partial nasolacrimal duct obstruction. Eye (Lond). 2011;25(9):1219-1224.

4. Sahlin S, Rose GE. Lacrimal drainage capacity and symptomatic improvement after dacryocystorhinostomy in adults presenting with patent lacrimal drainage systems. Orbit. 2001;20(3):173-179.

5. Tarbet KJ, Custer PL. External dacryocystorhinostomy. Surgical success, patient satisfaction, and economic cost. Ophthalmology. 1995;102(7): 1065-1070.

6. Amin M, Moseley IF, Rose GE. The value of intubation dacryocystography after dacryocystorhinostomy. Br J Radiol. 2000;73(870):604-607.

7. Lee MJ, Khwarg SI, Choung HK, Kim N. Associated factors of functional failure of external dacryocystorhinostomy. Can J Ophthalmol. 2014;49(1):40-44.

8. Munk PL, Lin DT, Morris DC. Epiphora: treatment by means of dacryocystoplasty with balloon dilation of the nasolacrimal drainage apparatus. Radiology. 1990;177(3):687-690.

9. Huang D, Swanson EA, Lin CP, et al. Optical coherence tomography. Science. 1991;254(5035):1178-1181.

10. Mak H, Xu G, Leung CK. Imaging the iris with swept-source optical coherence tomography: relationship between iris volume and primary angle closure. Ophthalmology. 2013;120(12):2517-2524.

11. Yeh RY, Quilendrino R, Musa FU, Liarakos VS, Dapena I, Melles GR. Predictive value of optical coherence tomography in graft attachment after Descemet's membrane endothelial keratoplasty. Ophthalmology. 2013;120(2):240-245.

12. Ibrahim OM, Dogru M, Takano Y, et al. Application of visante optical coherence tomography tear meniscus height measurement in the diagnosis of dry eye disease. Ophthalmology. 2010;117(10):1923-1929.
13. Park DI, Lew H, Lee SY. Tear meniscus measurement in nasolacrimal duct obstruction patients with Fourier-domain optical coherence tomography: novel three-point capture method. Acta Ophthalmol (Copenh). 2012;90(8):783-787.

14. Johnson ME, Murphy PJ. The agreement and repeatability of tear meniscus height measurement methods. Optom Vis Sci. 2005;82(12): $1030-1037$.

15. Kinoshita S, Awamura S, Oshiden K, Nakamichi N, Suzuki H, Yokoi N; Rebamipide Ophthalmic Suspension Phase II Study Group. Rebamipide (OPC-12759) in the treatment of dry eye: a randomized, doublemasked, multicenter, placebo-controlled phase II study. Ophthalmology. 2012;119(12):2471-2478.

16. Higuchi K, Arakawa T, Nebiki H, et al. Rebamipide prevents recurrence of gastric ulcers without affecting Helicobacter pylori status. Dig Dis Sci. 1998;43(9)(suppl):99S-106S.

17. Naito $\mathrm{Y}$, Yoshikawa T, Iinuma S, et al. Rebamipide protects against indomethacin-induced gastric mucosal injury in healthy volunteers in a double-blind, placebo-controlled study. Dig Dis Sci. 1998;43(9) (suppl):83S-89S.

18. Peter NM, Pearson AR. External dacryocystorhinostomy for the treatment of epiphora in patients with patent but non-functioning lacrimal systems. Br J Ophthalmol. 2010;94(2):233-235.

19. Smirnov G, Tuomilehto H, Kokki H, et al. Symptom score questionnaire for nasolacrimal duct obstruction in adults - a novel tool to assess the outcome after endoscopic dacryocystorhinostomy. Rhinology. 2010; 48(4):446-451.

20. Kim SE, Lee SJ, Lee SY, Yoon JS. Outcomes of 4-snip punctoplasty for severe punctal stenosis: measurement of tear meniscus height by optical coherence tomography. Am J Ophthalmol. 2012;153(4):769-773.

21. Roh JH, Chi MJ. Efficacy of dye disappearance test and tear meniscus height in diagnosis and postoperative assessment of nasolacrimal duct obstruction. Acta Ophthalmol (Copenh). 2010;88(3):e73-e77.

22. Mishima S, Gasset A, Klyce SD Jr, Baum JL. Determination of tear volume and tear flow. Invest Ophthalmol. 1966;5(3):264-276.
Clinical Ophthalmology

\section{Publish your work in this journal}

Clinical Ophthalmology is an international, peer-reviewed journal covering all subspecialties within ophthalmology. Key topics include: Optometry; Visual science; Pharmacology and drug therapy in eye diseases; Basic Sciences; Primary and Secondary eye care; Patient Safety and Quality of Care Improvements. This journal is indexed on

\section{Dovepress}

PubMed Central and CAS, and is the official journal of The Society of Clinical Ophthalmology (SCO). The manuscript management system is completely online and includes a very quick and fair peer-review system, which is all easy to use. Visit http://www.dovepress.com/ testimonials.php to read real quotes from published authors. 